\title{
Quantitative recovery of immunoreactive proteins from clinical samples following RNA and DNA isolation
}

\author{
Subhasis Banerjee, Alan Smallwood, Anne E. Chambers, \\ and Kypros Nicolaides \\ King's College Hospital Medical School, London, UK
}

BioTechniques 35:450-456 (September 2003)

The analysis of clinical biopsies poses unique problems for the biologist because of the tissue limitation and availability and has instigated the drive to develop and optimize methods that maximize data collection. One of the most extensively used methods for RNA/DNA purification from small quantities of tissue of diverse biological origin is extraction with acid guanidinium thiocyanate-phenol-chloroform (1-6), commercially produced as TRIzOL ${ }^{\circledR}$ reagent (Invitrogen, Carlsbad, CA, USA). In addition to the better recovery of total RNA compared to the guanidium thiocyanate-cesium chloride method $(7,8)$, a distinct advantage of this procedure is that RNA, DNA, and proteins can be recovered from the same tissue. Here we demonstrate that a significant increase in the quantitative recovery of protein occurs following alcohol precipitation in the presence of glycogen and solubilization at higher $\mathrm{pH}(8.0-8.8)$ in the presence of N-lauryl-sarkosine (sarkosyl), compared to that in standard sodium dodecyl sulfate (SDS)-polyacrylamide gel buffer (9). We substantiate the results by Western blot analyses using antibodies that recognize epitopes of glycosylated and nonglycosylated proteins.

To test whether standard SDS-polyacrylamide gel loading buffer conditions (9) are sufficient for the quantitative extraction of protein, human chorionic villous tissues $(50 \mathrm{mg})$ were dissected from placenta and stored in RNAlater ${ }^{\mathrm{TM}}$ (Ambion, Huntingdon, UK) at $-20^{\circ} \mathrm{C}$ before homogenization in $500 \mu \mathrm{L}$ TRIzOL, using a disposable pestle (Anachem, Luton, UK) in a 1.5-mL microfuge tube. The RNA, DNA, and proteins were sequentially extracted according to the manufacturer's instructions. The final phenol-chloroform-ethanol phase was divided into five aliquots (equivalent to $10 \mathrm{mg}$ tissue in each) before the isopropanol precipitation of the proteins. Duplicate pellets were washed (7) and dried before resuspension in $100 \mu \mathrm{L}$ buffer (containing 1\% SDS and $50 \mathrm{mM}$ Tris-Cl, pH 6.8, 7.5, 8.0, or 8.8). Proteins were solubilized by incubation at $50^{\circ} \mathrm{C}$ for $1 \mathrm{~h}$ with occasional vortex mixing. An $80-\mu \mathrm{L}$ aliquot of clear supernatant was transferred to a fresh tube while the tubes were held in a water bath. This step is necessary because the extracts become cloudy at room temperature $\left(22^{\circ}-25^{\circ} \mathrm{C}\right)$ due to the high SDS concentrations in the buffer. A quarter $(20 \mu \mathrm{L})$ of each sample (equivalent to $2.5 \mathrm{mg}$ tissue) was diluted by the addition of $5 \mu \mathrm{L}$ SDS-polyacrylamide gel loading buffer without SDS [313 mM Tris-Cl, pH 6.8, $50 \mathrm{mM}$ dithiothreitol (DTT), $0.05 \%$ bromophenol blue, and 50\% glycerol] and heated at $95^{\circ} \mathrm{C}$ for $5 \mathrm{~min}$ before loading on $10 \%$ polyacrylamide gels $(0.8-1.5$ $\mathrm{mm}$ thickness). Figure 1A shows (lanes 2-9) that the recovery of high molecular weight $\left(M_{\mathrm{r}}\right)$ proteins (above $M_{\mathrm{r}} 36$ $\mathrm{kDa}$ ) was lowest when the pellet was extracted using standard SDS-loading buffer conditions at $\mathrm{pH} 6.8$ and highest at $\mathrm{pH}$ 8.8. Therefore, it appears that high $\mathrm{pH}$ improves the extraction of high molecular weight proteins from the TRIzOL pellet, while having little effect on those of low molecular weight. Densitometric scanning of the thick band at approximately $M_{\mathrm{r}} 62 \mathrm{kDa}$ revealed that the yield of high molecular weight proteins, at $\mathrm{pH} 7.5,8.0$, and 8.8, compared to that at $\mathrm{pH} 6.8$, increased by $54 \%, 79 \%$, and $98 \%$, respectively. Nevertheless, such analysis of a single band might not reflect the $\mathrm{pH}$ effect on the recovery of all of the proteins. To account for this as well as loading differences, the experiment (Figure 1A) was repeated using different tissue samples (villous tissues from 12- and 39-week pregnancies and Down syndrome-affected fetal brain), and the total protein concentration in each extract was measured in duplicate [Lowry assay, detergent-compatible (DC) substrates; Bio-Rad Laboratories, Hemel Hempstead, UK]. These analyses showed that the average increase in yield of the total protein from TRIzOL pellets at $\mathrm{pH}$ 8.0-8.8 was from 2.2- to 2.4-fold higher $( \pm 0.33$ and \pm 0.41 , respectively) compared to that at pH 6.8 (Figure 1A).

To establish the minimum amount of tissue that could be extracted, the phenol-chloroform-ethanol supernatants obtained from 10, 4, 2, and $1 \mathrm{mg}$ tissue were precipitated in the presence of $20 \mu \mathrm{g}$ glycogen (Roche Diagnostics, Lewes, UK), and the protein pellets were solubilized in $50 \mathrm{mM}$ Tris- $\mathrm{Cl}, \mathrm{pH}$ 8.0, and $1 \%$ SDS. The results shown in Figure 1A (lanes 11-14) suggest that proteins can be quantitatively recovered from as little as $1 \mathrm{mg}$ tissue (one-quarter and one-half of the total amount of protein extracted from 10 and $4 \mathrm{mg}$ tissues were loaded in tracks 11 and 12, respectively). While there is a quantitative recovery of proteins from different amounts of starting material, the relationship is clearly not linear (Figure 1A, lanes 11-14). The addition of glycogen during the precipitation of the TRIzOL supernatant increased the recovery of total protein by $1.62-( \pm 0.13 ; n=3)$, $1.38-( \pm 0.20 ; n=2)$, and 1.25- $( \pm 0.38$; $n=3$ ) fold at $\mathrm{pH} 6.8,8.0$, and 8.8, respectively (Figure 1A, compare lanes 6 and 7 to 11; Figure 1D, lanes 9 and 10; and data not shown). Similarly, the addition of $62.5 \mathrm{mM}$ sarkosyl to both low $\mathrm{pH}$ (Figure 1A, lanes 16 and 17; pH 6.8) and high $\mathrm{pH}$ (Figure 1A, lanes 18 and 19; $\mathrm{pH}$ 8.8) SDS-solubilization buffers significantly increased the yield (>50\%) of protein from the precipitated pellets. To further examine the additive effect of sarkosyl, proteins from chorionic villi were directly extracted (without TRIzOL treatment) using $1 \%$ SDS or tissue protein extraction reagent $(\mathrm{T}$ PERTM; Perbio, Helsingborg, Sweden) in the presence and absence of 62.5 $\mathrm{mM}$ sarkosyl. No significant additive effect of sarkosyl was observed when protein was extracted in this way (Fig- 

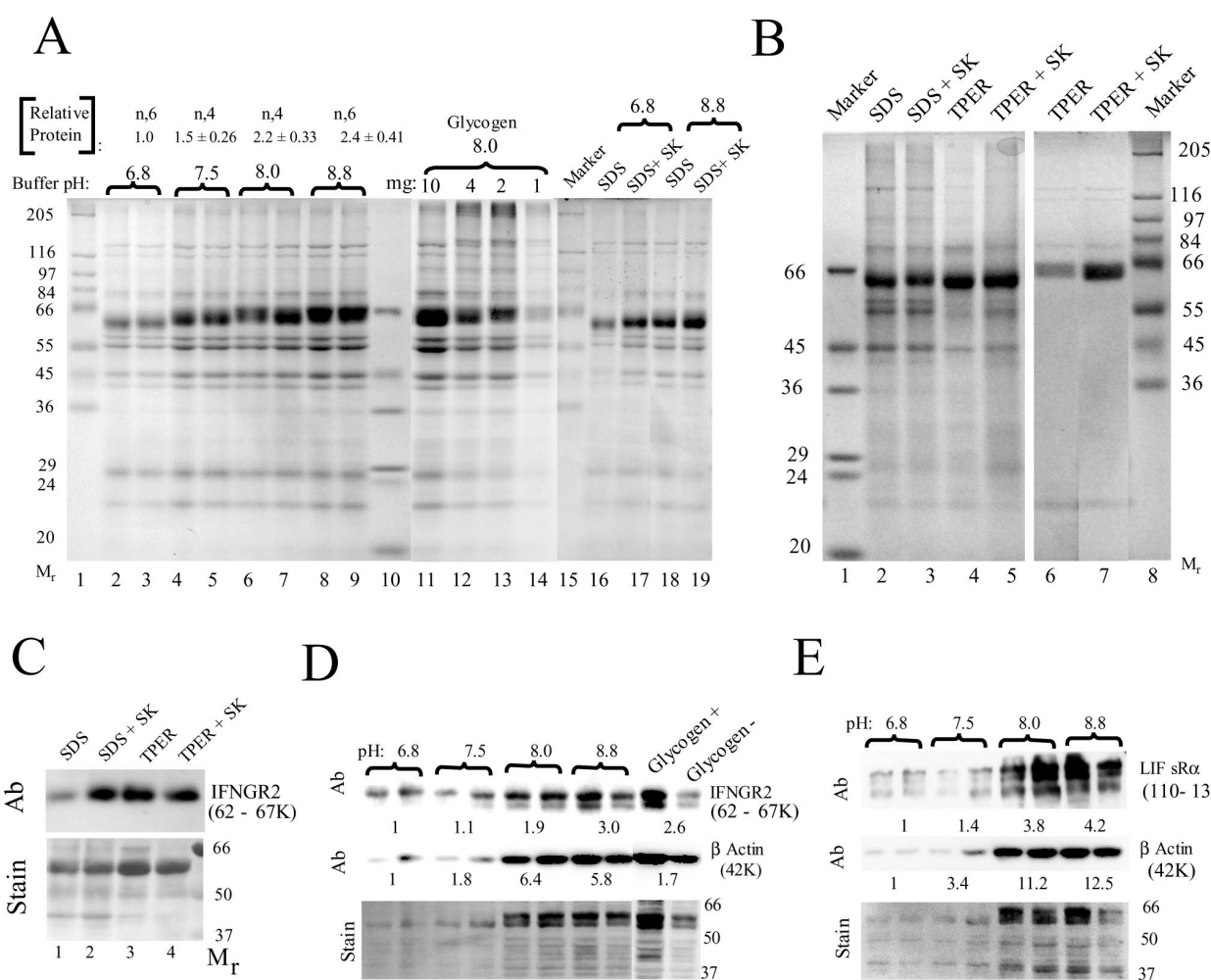

$\mathrm{D}$

$\mathrm{E}$
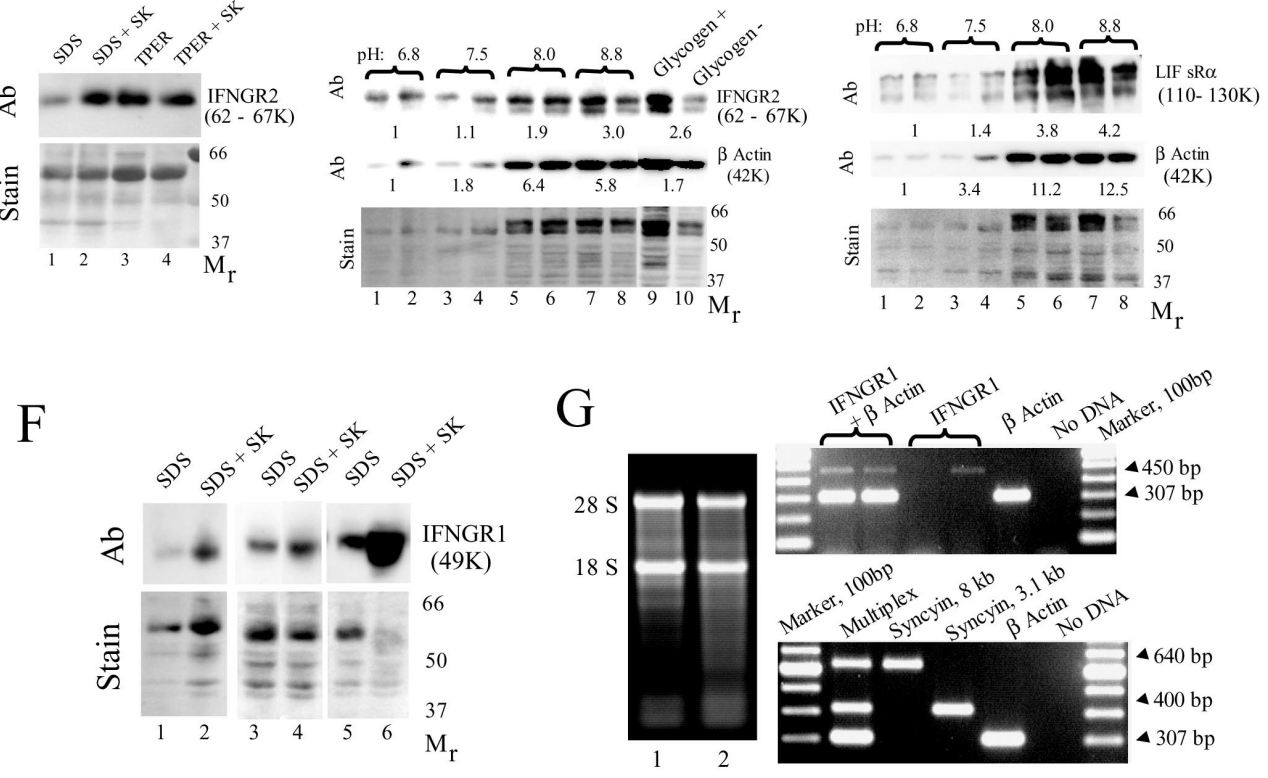

Figure 1. Comparison of yield and immunoreactivity of proteins from chorionic villous samples extracted and solubilized with different reagents. (A) Glycogen, at a high pH, and sarkosyl (SK) increased the solubility of proteins in TRIzoL protein pellets from villous tissue (39-week pregnancy). Protein pellets, precipitated from TRIzoL supernatants in the absence of glycogen, were extracted with $50 \mathrm{mM}$ Tris-Cl buffer at the $\mathrm{pH}$ indicated from the equivalent of $2.5 \mathrm{mg}$ tissue (lanes 2-9), from 1-10 mg tissue precipitated in the presence of glycogen (lanes 11-14; in lane 11, $2.5 \mathrm{mg}$ tissue equivalent were loaded and, in lane 12, $2 \mathrm{mg}$ tissue equivalent were loaded), and from $2 \mathrm{mg}$ tissue with or without sarkosyl at pH 6.8 (lanes 16 and 17) and at pH 8.8 (lanes 18 and 19). Protein concentrations from six different experiments were measured, and the mean ( $\overline{\mathrm{x}} \pm$ SEM) relative increase in recovery at $\mathrm{pH} 7.5,8.0$, and 8.8 , compared to that at $\mathrm{pH} 6.8$, are shown (lanes 2-9). Patient samples were villous tissues from two 39-week (39- and 38.4-week, caesarean delivery), two 12-week (12- and 12.1-week, voluntary termination of pregnancy) pregnancies, and fetal brain (13.1-week with Down syndrome). (B) Lanes 2-5, proteins were directly extracted from $50 \mathrm{mg}$ villous tissue (39-week pregnancy) at $\mathrm{pH}$ 8.0, tissue protein extraction reagent (T-PER), and from TRIzoL pellets (lanes 6 and 7). (C) Villous proteins (38.4-week pregnancy) extracted directly (lanes 1-4) at conditions indicated were resolved in 10\% sodium dodecyl sulfate (SDS)-polyacrylamide gels, electrotransferred to Immobilon polyvinylidene difluoride (PVDF) membrane, immunostained [upper panel; antibody (Ab)] with affinity-purified polyclonal goat anti-human interferon $\gamma$ receptor (IFNGR) 2, and membranes were then stained with $0.25 \%$ Coomassie blue (lower panel; stain). (D) Similar experiment to panel A (lanes 2-9), except that villous tissue was from a 12-week pregnancy and the proteins transferred to a PVDF membrane were first immunoreacted with anti-human IFNGR 2 antibody, and, subsequently, the membrane was stripped and reprobed with $\beta$-actin antibody. Fold increase in staining at different $\mathrm{pHs}$ compared to that at $\mathrm{pH} 6.8$ is shown below the bands; lanes 9 and 10, proteins were extracted at $\mathrm{pH} 8.8$, and fold-increase by glycogen is shown for IFNGR 2 and $\beta$-actin. (E) Similar experiment (villous tissue from a 12.1-week pregnancy) to panel D, except it was first immunostained with anti-human leukemia inhibitory factor-soluble receptor $\alpha$ (LIF-sR $\alpha$ ) and subsequently with $\beta$-actin. (F) Villous proteins (38.4-week pregnancy) were extracted at pH 6.8 (lanes 1 and 2), pH 8.0 (lanes 3 and 4), and pH 8.8 (lanes 5 and 6) in the presence and absence of sarkosyl. (G) RNA analysis from samples used for protein extraction; lanes 1 and 2, $5 \mu \mathrm{g}$ total RNA from experiments shown in panels A-C and $\mathrm{F}$ (two 39-week villous tissue) were resolved on agarose gel, which demonstrated the quality of 28S and 18S ribosomal RNAs; the cDNA prepared from 12-week (Figure 1D) and 39-week pregnancies (A) were used to amplify IFNGR1 (forward, 5'-GAATGAACGGAAGTGAGATCCA-3' and reverse, 5'-CCTGGAACTGTTGCTGGAGA-3'), 8.0 (forward, 5'-TCAGGGATAGCCCCCATCTAT-3' and reverse, 5'-AACCCTTTGCCACTACATCAATTT-3'), and $3.1 \mathrm{~kb}$ (forward, 5'-CCGCTGAAAGAGGGGGAA-3' and reverse, $5^{\prime}$-TAGAGGTTGTGCAGCTGAGA-3') Syncytin, and $\beta$-actin (forward, $5^{\prime}$-CTTCTACAATGAGCTGGGTG-3' and reverse, 5'-TCATGAGGTAGTCAGTCAGG-3') mRNAs alone or together (multiplex), as previously described (10). 
ure 1B, lanes 2-5); however, sarkosyl did increase the yield of the $M_{\mathrm{r}} 62 \mathrm{kDa}$ protein from TRIzOL pellets when it was added to T-PER in the absence of $1 \%$ SDS (Figure 1B, lanes 6 and 7). The lack of extraction of the majority of the proteins below $M_{\mathrm{r}} 62 \mathrm{kDa}$ (Figure $1 \mathrm{~B}$, lanes 6 and 7) suggests that SDS is absolutely essential for the quantitative extraction of proteins from TRIzOL pellets. When the yield of protein from 10 mg tissue extracted by different methods was compared, direct extraction (SDS or T-PER) yielded between 410-530 $\mu \mathrm{g}$, while TRIzOL pellet yields ranged 165-390 $\mu \mathrm{g}(165 \mu \mathrm{g}, \mathrm{pH} 6.8 ; 335 \mu \mathrm{g}$, $\mathrm{pH} 8.0$; and $390 \mu \mathrm{g}, \mathrm{pH} 8.8)$. It is possible that the yield of proteins is reduced by the high salt in RNAlater.

The effects of $\mathrm{pH}$, glycogen, and sarkosyl on the retrieval of proteins from TRIzOL pellets were verified (Figure 1, C-F) by the Western transfer of proteins to Immobilon ${ }^{\mathrm{TM}}$ polyvinylidene difluoride (PVDF) membranes (Millipore, Watford, UK), followed by detection using antibodies raised against various epitopes [human interferon $\gamma$ receptors (IFNGR) 1 and 2; human leukemia inhibitory factor-soluble receptor $\alpha$ (LIF $\mathrm{sR} \alpha$ ) (R\&D Systems, Oxford, UK); $\beta$-actin, clone AC-15 (Sigma, Poole, Dorset, UK)]. Immunostained Western blots were developed using chemiluminescence reagents (Lumi-Light and

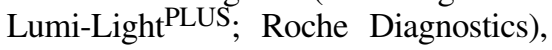
and the yield of immunostained protein in each condition was measured by densitometry scanning of the developed autoradiographs. The Western blots were then stained with Coomassie Brilliant Blue $\mathrm{R}^{\circledR}$ (Sigma), and the yield of immunoreactive protein was normalized to the intensity of the $M_{\mathrm{r}} 62 \mathrm{kDa}$ band in the lane of the Coomassie stained blot.

Although sarkosyl failed to increase the yield of proteins using the direct extraction of tissues with $1 \%$ SDS in the absence of TRIzOL (Figure 1B, lanes 2 and 3), it did increase the release of immunoreactive IFNGR 1 and 2 proteins from 2 - to 3 -fold when compared to that in the presence of $1 \%$ SDS alone (Figure 1C, compare lane 1 to 2; and data not shown). Accordingly, the effect of buffer $\mathrm{pH}$ on the recovery of proteins from the TRIzOL pellet observed by Coomassie gel staining (Figure 1A, lanes 2-9) was substantiated by the Western data (Figure 1, D and E). However, of four proteins of different molecular weights and levels of glycosylation tested (IFNGR 1 and 2 , LIF $\operatorname{sR} \alpha$, and $\beta$-actin), the effect of a high $\mathrm{pH}(8.0-8.8)$ on the recovery of $\beta$-actin was the highest (from 6- to 12-fold compared to that at $\mathrm{pH} 6.8$ ), followed by LIF $\mathrm{sR} \alpha$ (4-fold), and then IFNGR 1 and 2 were the lowest (from 2- to 3-fold) (Figure 1, D and E; and data not shown). Therefore, the protein profile in stained SDS-polyacrylamide gels (Figure 1A) is not necessarily a reflection of the recovery of a specific immunoreactive protein. As observed by direct extraction (Figure 1C), sarkosyl significantly increased (from 3- to 6 -fold) the recovery of IFNGR 1 from TRIzOL pellets at both low $\mathrm{pH}$ (Figure $1 \mathrm{~F}$, lanes 1 and $2 ; \mathrm{pH} 6.8$ ) and high $\mathrm{pH}$ (Figure 1F, lanes 3-6; pH 8.0-8.8).

To ensure that other macromolecules were recovered from the tissues used for the TRIzOL extraction of protein pellets, the corresponding genomic
DNA and RNA pellets (Figure 1, A-F) were saved and analyzed. The $28 \mathrm{~S}$ and 18S RNA resolved on agarose gel (Figure $1 \mathrm{G}$, lanes 1 and 2) and Northern blot hybridization to $3-8 \mathrm{~kb}$ mRNAs (10) suggest that cellular RNAs were intact during TRIzOL extraction. These results were confirmed by the specific amplification of a variety of genes (syncytin, 8 and $3.1 \mathrm{~kb}$ mRNAs; IFNGR1, $2.1 \mathrm{~kb}$ mRNA) using standard PCR from cDNAs prepared from these samples (Figure 1G) and realtime PCR (manuscript in preparation). The genomic DNA obtained following TRIzOL extraction was digestable with restriction enzymes EcoRI and TaqI (data not shown). These results are fully consistent with the original report that described the simultaneous isolation of RNA, DNA, and proteins (7).

\section{ACKNOWLEDGMENTS}

We thank the King's College Hospital ethics committee for approval and the patients for providing written consent to obtain placental and chorionic villous samples and fetal tissues. This study was supported by The Fetal Medicine Foundation, London, UK.

\section{REFERENCES}

1.Barbaric, D., L. Dalla-Pozza, and J.A. Byrne. 2002. A reliable method for total RNA extraction from frozen human bone marrow samples taken at diagnosis of acute leukaemia. J. Clin. Pathol. 55:865-867.

2.Kramer, L.D., T.M. Wolfe, E.N. Green, R.E. Chiles, H. Fallah, Y. Fang, and W.K. Reisen. 2002. Detection of encephalitis viruses in mosquitoes (Diptera: Culicidae) and avian tissues. J. Med. Entomol. 39:312-323.

3.Baelde, H.J., A.M. Cleton-Jansen, H. van Beerendonk, M. Namba, J.V. Bovee, and P.C. Hogendoorn. 2001. High quality RNA isolation from tumours with low cellularity and high extracellular matrix component for cDNA microarrays: application to chondrosarcoma. J. Clin. Pathol. 54:778-782.

4.Hofmann, M.A., B. Thur, L. Liu, M. Gerber, P. Stettler, C. Moser, and S. Bossy. 2000. Rescue of infectious classical swine fever and footand-mouth disease virus by RNA transfection and virus detection by RT-PCR after extended storage of samples in Trizol. J. Virol. Methods 87:29-39.

5.Gandini, O., F.S. Celi, M. Magnanti, P. Gazzaniga, I. Silvestri, B. Conti, L. Giuliani, D. Mentuccia, et al. 1999. A rapid, simple, and inexpensive step facilitates RNA extraction from 
whole blood cells. Lab. Invest. 79:1731-1732.

6.Verhofstede, C., K. Fransen, D. Marissens, R. Verhelst, G. van der Groen, S. Lauwers, G. Zissis, and J. Plum. 1996. Isolation of HIV-1 RNA from plasma: evaluation of eight different extraction methods. J. Virol. Methods 60: 155-159.

7.Chomczynski, P. 1993. A reagent for the singlestep simultaneous isolation of RNA, DNA and proteins from cell and tissue samples. BioTechniques 15:532-537.

8.Chomczynski, P. and N. Sacchi. 1987. Singlestep method of RNA isolation by acid guanidinium thiocyanate-phenol-chloroform extraction. Anal. Biochem. 162:156-159.

9.Laemmli, U.K. 1970. Cleavage of structural proteins during the assembly of the head of bacteriophage T4. Nature 227:8680-8685.
10.Smallwood, A., A. Papageorghiou, K. Nicolaides, M.K. Alley, J. Alice, G. Nargund, K. Ojha, S. Campbell, and S. Banerjee. Temporal regulation of the expression of Syncytin (HERV$W$ ), maternally imprinted $P E G 10$, and SGCE in human placenta. Biol. Reprod. (In press). Biol. Reprod. 2003 Mar 5 (Epub ahead of print).

Received 17 March 2003; accepted 28 May 2003.

Address correspondence to Subhasis Banerjee, Harris Birthright Research Centre for Fetal Medicine, King's College Hospital Medical School, Denmark Hill, London SE5 9RS, UK.e-mail:dr_sbanerjee@hotmail.com

\title{
Selection of optimal internal controls for gene expression profiling of liver disease
}

\author{
Soyoun Kim and Taeuk Kim \\ LG Chem Ltd./Research Park, Daejeon, Korea
}

BioTechniques 35:456-460 (September 2003)

Recently developed technologies such as microarray analysis allow researchers to determine the genome-wide patterns of expressed genes. This information provides insight into complex regulatory networks, enables the identification of new or underexplored biological processes, and implicates genes in various disease processes (1). While microarray analysis provides genome-wide information on relative gene expression, real-time reverse transcription-PCR (RT-PCR) provides quantitative information by the simultaneous measurement of gene expression in many different samples, which makes the technique especially suitable for research questions that require the measurement of expression level changes (2). Compared to conventional quantification methods such as Northern blot analysis, RNase protection assay, or competitive RTPCR, real-time RT-PCR analysis has the advantages of greater speed, higher throughput, and a higher degree of potential automation $(3,4)$. Nevertheless, all strategies for mRNA quantification require accurate, reproducible normal- ization. For the correct normalization of gene expression analysis, various strategies have been applied, such as counting cells, total RNA quantitation, and rRNA measurement (3). However, internal control genes are most frequently used to normalize mRNA expression in laboratory experiments. The internal control, usually one of the so-called housekeeping genes (5), should not vary between the tissues or cells under investigation or in response to experimental treatment. However, although housekeeping genes are constant in certain cell types, they can vary in other types $(6,7)$, particularly in clinical samples associated with malignant diseases (5). Thus, the selection of proper control genes for clinical patient samples is vital to gene expression analysis.

In the current study, we used liver tissues from normal, liver cirrhosis (LC), and hepatocellular carcinoma (HCC) patients to examine the expression patterns of housekeeping genes. Liver cancer is the third most deadly cancer worldwide and fifth in the number of cases (8), but the molecular mechanisms of hepatocarcinogenesis are not well understood. Therefore, the number of studies probing global gene expression profiles of HCC or preneoplastic chronic liver disease has increased exponentially in recent years $(9,10)$, and the identification of the optimal internal controls is necessary for correct gene expression profiling of liver diseases.

Table 1 describes the 10 common housekeeping genes and gene-specific primers that were used. To compare the expression levels of each housekeeping gene, we used four different groups of liver tissues: normal liver tissues, LC, nontumor LC tissues from an HCC patient, and carcinoma tissues from an HCC patient. The expression level of the 10 internal control genes was determined by real-time RT-PCR analysis, with RNAs extracted from the same amount of 10 different liver tissue samples. Table 2 shows the expression level of each tissue sample. To evaluate the expression stability of each housekeeping gene between liver tissues, we used the geNorm program (3). The geNorm program determines the most stable housekeeping genes from a set of tested genes and calculates the gene expression normalization factor for all tissue samples, based on the geometric mean of a user-defined number of housekeeping genes. The results are ranked and shown in Table 2. From geNorm analysis, the ubiquitin $\mathrm{C}(U B C)$ gene showed the most stable expression between 10 liver samples, with the hydromethyl-bilane synthase $(H M B S)$ gene a close second. In addition, the stepwise exclusion of the least stable gene showed $U B C$ and $H M B S$ as the most stable genes (data not shown).

Next, we assessed the stability of the $U B C$ and $H M B S$ genes in 67 additional normal, LC, nontumor LC tissues from an HCC patient, and HCC samples. The stability of these two genes as assessed by geNorm analysis (M value: 3) was 1.02. Because perfect stable expression should result in $\mathrm{M}$ values of zero, the geometric mean of the $U B C$ and $H M B S$ gene results is a very accurate control for liver tissues, as compared to the other commonly used housekeeping genes shown in Table 2. In a study of 67 liver tissues, analysis using the geNorm program showed that the $U B C$ 